\title{
Conservação pós-colheita de melão Charentais tratado com 1-MCP e armazenado sob refrigeração e atmosfera modificada
}

\author{
Pahlevi A de Souza'; Fernando Luiz Finger²; Ricardo Elesbão Alves³; Mário Puiatti²; Paulo R Cecon²; \\ Josivan B Menezes ${ }^{1}$ \\ ${ }^{1}$ UFERSA-Depto. Ciências Ambientais, 59625-900 Mossoró-RN; ${ }^{2}$ UFV, 36570-000 Viçosa-MG; ${ }^{3}$ Embrapa Agroindústria Tropical, R. \\ Dra. Sara Mesquita, 2270, Planalto Pici, 60511-110 Fortaleza-CE; pahlevi10@ hotmail.com
}

\begin{abstract}
RESUMO
Objetivando avaliar a vida útil pós-colheita de melão tipo Charentais (Cucumis melo L.) sob refrigeração, tratados com 1-MCP e associado ou não a atmosfera modificada (AM), foram conduzidos dois experimentos em laboratório da Embrapa Agroindústria Tropical, Fortaleza-CE. Os frutos foram provenientes da Agroindústria Nolem Comercial Importadora e Exportadora Ltda, localizada no Agropólo Mossoró Açu-RN. Os frutos foram tratados com 300 e $600 \mathrm{ppb}$ de 1-MCP, em seguida, metade desses frutos foram embalados em filmes plásticos, mantendo-se frutos embalados sem aplicação de 1-MCP nas mesmas condições de armazenamento dos demais. Os melões foram armazenados por 21 dias sendo 14 dias $\left(9 \pm 1^{\circ} \mathrm{C}\right.$ e $87 \pm 5 \%$ UR $)+7$ dias $\left(22 \pm 2^{\circ} \mathrm{C}\right.$ e $70 \pm 5 \%$ UR). Em função da aparência externa, a vida útil pós-colheita dos frutos armazenados sob atmosfera modificada, com ou sem tratamento inicial de 1-MCP foi de 21 dias, enquanto que dos frutos tratados inicialmente apenas com 1-MCP foi de 19 dias. A aplicação do 1-MCP proporcionou redução na atividade respiratória e na produção de etileno, e maior retenção da firmeza da polpa, menor perda de massa e melhor aparência externa quando associado a atmosfera modificada. A atmosfera modificada, isoladamente, foi eficiente em reduzir a perda de massa e manter melhor aparência externa.
\end{abstract}

Palavras-chave: Cucumis melo L., armazenamento, etileno, filme plástico.

\begin{abstract}
Postharvest conservation of charentais melons treated with 1-MCP and stored under refrigeration and modified atmosphere

Aiming to evaluate the postharvest shelf life of Charentais melon (Cucumis melo L.) stored under refrigeration, the fruits were treated with 1-MCP, associated or not with modified atmosphere (MAP). Two experiments were carried out at the laboratory of Embrapa Agroindústria Tropical in Fortaleza, Brazil, analyzing the chemical and physic quality characteristics. The fruits were obtained at the Agroindústria Nolem Comercial Importadora e Exportadora Ltda, located in Mossoró Açu, Brazil. The fruits were treated with 300 and $600 \mathrm{~nL} \mathrm{~L}^{-1}$ of 1-MCP, half of those were wrapped in plastic films, which were wrapped without the use of 1-MCP in the same conditions of storage. The melons were stored during 21 days, being 14 days $\left(9 \pm 1^{\circ} \mathrm{C}\right.$ and $87 \pm 5 \%$ UR $)+7$ days $\left(22 \pm 2^{\circ} \mathrm{C}\right.$ and $70 \pm 5 \%$ UR). Based on external appearance, postharvest shelf life of the fruits stored under modified atmosphere, with or without initial treatment of 1-MCP was 21 days, while in fruits treated initially only with 1MCP, it was 19 days. The application of the 1-MCP provided reduction in the respiratory activity and ethylene production, and higher flesh firmness retention, smaller weight loss and better external appearance, when associated the modified atmosphere. The modified atmosphere, separately, was efficient to reduce the weight loss and to maintain better external appearance.
\end{abstract}

Keywords: Cucumis melo L., storage, ethylene, plastic film.

(Recebido para publicação em 12 de novembro de 2007; aceito em 17 de outubro de 2008) (Received in November 12, 2007; accepted in October 17, 2008)

\begin{abstract}
A região Nordeste, em função da adoção de tecnologias de irrigação eficientes, utilização de híbridos adaptados à região e das condições climáticas favoráveis existentes passou a ser a maior produtora de melão do Brasil, com cerca de $93,6 \%$ do total, seguida pela região Sul responsável por $4,8 \%$ (Agrianual, 2004). O estado do Rio Grande do Norte, com a maior parte de sua produção localizada no Agropólo Mossoró Açu, é o maior produtor da região Nordeste, com 55\% (IBGE, 2006), destacando-se também os estados do Ceará, Pernambuco e Bahia. Com isso, o Brasil passou de importador para exportador de melão, produzindo em 2004 cerca de 264.000 frutos de melão ao ano
\end{abstract}

em uma área de 14.000 ha. Segundo a Secretaria de Comércio Exterior do Ministério do Desenvolvimento, Indústria e Comércio Exterior (SEDEC/MIX), as exportações nacionais de melão tiveram acréscimo de $116 \%$ nos últimos sete anos, passando de 47,5 mil toneladas em 1997 para 98,74 mil toneladas em 2004, com valor de US\$ 37,8 milhões. Boa parte desta produção é destinada ao mercado externo, com cerca de $90 \%$ à União Européia, onde o Reino Unido é o principal importador, seguido da Holanda, Finlândia, Bélgica, Alemanha e Espanha (Moretti \& Araújo, 2003).

No pólo Rio Grande do Norte/Ceará, $70 \%$ da produção de melão é embala- da e o restante vendida a granel, sendo que metade do que é embalado é destinado à exportação: $90 \%$ para União Européia, e os $10 \%$ restantes para os EUA e Mercosul. Da outra metade embalada, cerca de $97 \%$ é destinada aos mercados localizados no centro sul do país, e os 3\% restantes são consumidos em nichos de mercados das regiões Norte e Nordeste (Araújo \& Vilela, 2003). As cultivares do grupo Inodorus, representadas pelo tipo Amarelo, Pele de Sapo e Orange Flesh, são os preferidos pelos produtores do pólo Rio Grande do Norte/Ceará, totalizando mais de 50\% da área plantada, preferência essa justificada pelos 30 a 35 dias de vida útil pós-colheita em condições ambien- 
te. Apesar disto, observa-se tendência de crescimento da área cultivada com melões Cantaloupensis como os Cantaloupes, Galias e Charentais, que são mais saborosos, mais adocicados e possuem maior valor nutritivo.

Entre os melões Cantaloupensis, o tipo Charentais vem ganhando destaque devido a sua aceitação por parte dos consumidores da principal região importadora, a União Européia. Os melões Charentais são bastante aromáticos, de origem francesa, que podem apresentar tanto casca lisa como reticulada, apresentando suturas ou costelas, com coloração variando de verde-escuro a cinza e formato variando de redondo a achatado. Apesar de se tratar de um produto com excelente qualidade, a vida útil desses melões, sob temperatura ambiente, é bastante limitada. Segundo Rodov et al. (2002), o tipo Charentais tem um pronunciado comportamento climatérico, sendo que em poucos dias após a colheita o fruto torna-se rapidamente maduro com amolecimento excessivo da polpa, presença de coloração amarelo-alaranjado da casca, deterioração do "flavor", declínio do conteúdo de açúcares e aumento na suscetibilidade a patógenos.

O controle de qualidade pré e póscolheita do melão produzido no Nordeste se faz necessário devido à distância dos principais mercados, pois para ser transportado via terrestre, sem refrigeração até São Paulo, o melão leva em torno de 5 dias e para ser transportado até o porto de Roterdam na Holanda, por transporte marítimo sob refrigeração, gasta-se de 11 a 12 dias, e de 10 a 14 dias o tempo necessário de transporte marítimo até o porto da Filadélfia no leste dos EUA.

$\mathrm{O}$ armazenamento sob baixas temperaturas constitui o meio mais efetivo na extensão da vida útil pós-colheita de frutos e hortaliças e como complemento da refrigeração, a modificação ou controle da atmosfera vem sendo utilizado com sucesso. A atmosfera modificada (AM) pode ser definida como o armazenamento realizado sob condições de composição da atmosfera diferente daquela presente na atmosfera do ar normal (Lana \& Finger, 2000). Níveis baixos de $\mathrm{O}_{2}(<8 \%)$ e altos de $\mathrm{CO}_{2}$
$(>1 \%)$ na atmosfera em torno do produto reduzem a taxa respiratória e conseqüentemente a perda de água, síntese e ação de etileno, mudanças nos ácidos e nos açúcares, mudanças na cor e textura, incidência de injúria pelo frio e desordens fisiológicas, incidências de microorganismos, decorrentes do retardamento do amadurecimento e senescência, prolongando a vida útil pós-colheita do produto (Hulbert \& Bhowmik, 1987; Nakhasi et al., 1991).

Novas técnicas têm sido utilizadas para aumentar a vida-útil pós-colheita de frutos e hortaliças. Uma delas é a utilização de inibidores da ação do etileno, como o 1-metilciclopropeno (1-MCP). O 1-MCP é um composto gasoso que bloqueia a ação do etileno, através de competição pelos sítios de ligação com os receptores nas membranas celulares, reduzindo os efeitos do etileno procedente de fontes internas e externas (Blankenship \& Dole, 2003). Watkins (2006), em sua revisão sobre o uso do 1MCP em frutos e hortaliças, encontrou efeitos desse composto sobre a atividade respiratória, produção de etileno, pigmentos e metabolismo da parede celular, entre outros. Segundo Blankenship \& Dole (2003), o 1-MCP possui diferentes efeitos sobre o amadurecimento e qualidade de frutos e hortaliças de comportamento climatérico ou não, vários fatores como a concentração do gás 1MCP necessário para saturar os receptores e competir com o etileno, tempo de aplicação, temperatura ideal para que o tratamento seja efetivo e grau de maturação do produto, pois o 1-MCP não é efetivo em maturação avançada, podem influenciar os tratamentos (Chitarra \& Chitarra, 2005). Dessa forma, o tratamento do melão Charentais com 1-MCP pode favorecer a exploração de mercados mais distantes e permitir maior elasticidade para oferta do produto.

O objetivo do presente trabalho foi avaliar a conservação pós-colheita de melão Charentais tratado com 1metilciclopropeno (1-MCP) e armazenado sob refrigeração e atmosfera modificada.

\section{MATERIAL E MÉTODOS}

Melões Charentais 'Aura Prince' provenientes de plantio comercial da
Empresa Nolem Com. Imp. E Exportação Ltda., localizado em Mossoró-RN, foram colhidos com coloração verdeacinzentada e com a região em torno do pedúnculo sem sinais de abertura (préclimatérico). Após a colheita os frutos foram tratados pelo pincelamento ao redor do pedúnculo com solução contendo o fungicida Imazalil na concentração de $2 \mathrm{~mL} \mathrm{~L}^{-1}$, e transportados para o laboratório da Embrapa Agroindústria Tropical.

Após a seleção dos frutos, procedeuse os tratamentos com1-MCP (SmartFresh $^{\circledR}, 3,3 \%$ i.a.), nas concentrações 300 e 600 ppb, em câmaras herméticas com capacidade para $0,186 \mathrm{~m}^{3}$, utilizando-se 40 frutos para cada concentração. Os frutos foram expostos ao 1-MCP por 12 horas a temperatura de aproximadamente $25^{\circ} \mathrm{C}$. Após esse período, 20 frutos tratados com cada concentração de 1-MCP foram embalados em sacos plásticos de polietileno microperfurados Xtend ${ }^{\mathrm{o}}$ da empresa Stepac L. A., Ltd., Israel, colocando-se 4 frutos por saco. Segundo Rodov et al. (2002), o material apresenta espessura nominal de $20 \mathrm{~mm}$ com passagem de vapor de água de $25,0 \times 10^{-10} \mathrm{~mol} \mathrm{~m}^{-2} \mathrm{~s}^{-1}$ $\mathrm{Pa}$ e permeabilidade a $\mathrm{O}_{2}$ de $23,5 \times 10^{-14}$ mol m $\mathrm{m}^{-2} \mathrm{~s}^{-1} \mathrm{~Pa}$ a $23^{\circ} \mathrm{C}$ e $50 \%$ de UR. O restante dos frutos tratados com 1-MCP foi deixado sem a embalagem plástica. Para efeito de comparação foram mantidos frutos embalados com X-tend ${ }^{\circledR}$ sem aplicação de 1-MCP nas mesmas condições de armazenamento dos demais. Após a aplicação dos tratamentos os frutos foram armazenados por 21 dias sendo 14 dias $\left(9 \pm 1^{\circ} \mathrm{C}\right.$ e $87 \pm 5 \%$ UR), simulando-se o transporte marítimo para a Europa, +7 dias $\left(22 \pm 2^{\circ} \mathrm{C}\right.$ e $70 \pm 5 \%$ UR), simulando-se o período de comercialização, e avaliados nos seguintes tempos: $0 ; 7 ; 14 ; 14+3 ; 14+5$ e 14+7 dias. Após a saída da câmara fria (14 dias) todos os filmes plásticos foram abertos.

$\mathrm{O}$ delineamento experimental foi inteiramente casualizado, em esquema fatorial $5 \times 6$, onde o primeiro fator constou dos tratamentos (atmosfera modificada (AM) isolada, $300 \mathrm{ppb}$ de 1MCP+AM, 600 ppb+AM, 300 ppb e 600 ppb isolados) e o segundo dos tempos de armazenamento $(0 ; 7 ; 14 ; 17 ; 19 \mathrm{e}$ 
21 dias), com 4 repetições constituída de um fruto cada uma.

Para a avaliação da atividade respiratória (mg $\mathrm{CO}_{2} \mathrm{~kg}^{-1} \mathrm{~h}^{-1}$ ) e a produção de etileno $\left(\mu \mathrm{L} \mathrm{C} \mathrm{C}_{2} \mathrm{Hg}_{4} \mathrm{~kg}^{-1}\right)$, os frutos sob atmosfera modificada foram retirados dos sacos 2 horas antes das análises cromatográficas. Quatro frutos inteiros foram pesados e colocados em recipientes plásticos herméticos por $30 \mathrm{~min}$, sendo cada fruto considerado como uma repetição. Uma amostra de $5 \mathrm{~mL}$ de ar do interior dos recipientes foi retirada com uma seringa através do septo e injetada em cromatógrafo a gás CG modelo DANI 86.10 equipado com detector de condutividade térmica de $150^{\circ} \mathrm{C}$ $\left(\mathrm{CO}_{2}\right)$ e $200^{\circ} \mathrm{C}\left(\mathrm{C}_{2} \mathrm{H}_{4}\right)$, em coluna PORAPAK-N (4 m x 3 mm). Avaliouse a firmeza da polpa $(\mathrm{N})$ (resistência da polpa à penetração, utilizando-se penetrômetro manual modelo FT 327, com sonda de $8 \mathrm{~mm}$ de diâmetro sendo realizadas 4 leituras por fruto no centro da polpa na região equatorial do fruto); perda de massa (\%) (considerou-se a diferença entre a massa inicial do fruto e aquela obtida em cada intervalo da amostragem, com balança semi-analítica; aparência externa (nota de 5-1 onde $5=$ ausência de depressões, murcha ou ataque de microrganismos; $4=$ traços de depressões e/ou murcha; $3=$ leve depressões e/ou murcha; $2=$ depressões e/ou murcha com média intensidade e leve ataque de microrganismos e $1=$ depressões e murcha com intensidade severa e ataque fúngico)); aparência interna (nota de 5-1 onde $5=$ ausência de colapso na polpa, nem sementes soltas e/ou líquido na cavidade; $4=$ traços de colapso na polpa, de sementes soltas e/ou líquido na cavidade; $3=$ leve colapso na polpa, de sementes soltas e/ou líquido na cavidade; $2=$ colapso na polpa, sementes soltas e/ou líquido na cavidade, em intensidade média e 1= colapso na polpa, sementes soltas e/ou líquido na cavidade, em intensidade severa).

Os sólidos solúveis totais (SST, ${ }^{\circ}$ Brix) foram determinados em refratômetro digital ATAGO PR 101, escala de 0 a $45^{\circ}$, com compensação automática de temperatura; açúcares solúveis totais (AST, \%): extraídos em água e determinados com reagente Antrona, conforme Yemm \& Willis
(1954); vitamina C (mg.100g $\left.\mathrm{g}^{-1}\right)$ : por titulação com solução de Tillman (2,6 diclorofenol indofenol, DFI), conforme Strohecker \& Henning (1967); coloração da casca: por reflectometria, utilizando-se de um colorímetro Minolta Croma Meter CR-200b, calibrado em superfície de porcelana branca sob condições de iluminação ambiente e expressa no módulo $\mathrm{L}$ a* $\mathrm{b}^{*}$, posteriormente calculando-se o Ângulo hue (arco tangente $\left(b^{*} / a^{*}\right)$, realizando-se duas leituras (região equatorial e próximo ao pedúnculo); etanol: segundo metodologia proposta por Kato Noguchi \& Watada (1997), em cromatógrafo a gás (CG/DANI 86.10) equipado com coluna Porapak-N (4 m x 3 mm) e atividade da enzima poligalacturonase, segundo metodologia proposta por VilasBoas et al. (2000), com modificações.

A atividade respiratória e a produção de etileno não apresentaram homocedasticidade das variáveis, conforme teste de Bartlett, não sendo, portanto, submetidas a analise de variância, optando-se, em ambos os casos, por apresentar as médias das concentrações dos tratamentos em cada tempo.

Os dados foram submetidos à análise de variância e regressão utilizandose o Sistema de Análises Estatísticas e Genéticas da UFV (SAEG, UFV). Utilizou-se o teste de Tukey adotando o nível de $5 \%$ de probabilidade para a avaliação das médias.

\section{RESULTADOS E DISCUSSÃO}

De maneira geral, o armazenamento refrigerado reduziu a atividade respiratória até o $15^{\circ}$ dia (Figura $1 \mathrm{~A}$ ), ou seja, até um dia após a retirada da câmara fria, sendo esta mais intensa nos frutos tratados com 600 ppb de 1-MCP tanto na presença como na ausência da atmosfera modificada (AM). A partir de então, verificou-se aumento da atividade respiratória até o $19^{\circ}$ dia de armazenamento, com picos respiratórios isolados para os tratamentos $300 \mathrm{~nL}$ $\mathrm{L}^{-1}$ de 1-MCP e $300 \mathrm{~nL} \mathrm{~L}^{-1}$ de 1 $\mathrm{MCP}+\mathrm{AM}$ aos 16 e aos 19 dias, respectivamente. Foi observado, também, que o uso isolado da atmosfera modificada levou a redução da taxa respiratória podendo ser explicado pelo aumento da concentração de $\mathrm{CO}_{2}$ e redução do $\mathrm{O}_{2}$ no interior desta.

$A$ produção de etileno foi baixa durante o armazenamento refrigerado para todos os tratamentos estudados (Figura 1B). Após a retirada dos frutos da câmara fria observou-se alta produção de etileno com picos para todos os tratamentos ao $16^{\circ}$ dia. A partir desse ponto houve menor produção de etileno para os frutos tratados com 1-MCP. Esses valores estão acima dos encontrados por Almeida et al. (2001 a) em melões cantaloupe, que obtiveram taxas inferiores a $50 \mu \mathrm{L} \mathrm{kg}^{-1} \mathrm{~h}^{-1}$. Os mesmos autores também verificaram menor produção de etileno durante o armazenamento refrigerado. Estudando a supressão do amadurecimento e do amolecimento em melões Gália verdosos ou maduros tratados com 1-MCP e armazenados a $20^{\circ} \mathrm{C}$, Ergun et al., (2005) verificaram que o tratamento utilizando $1,5 \mu \mathrm{L} \mathrm{L}^{-1}$ de 1-MCP por $24 \mathrm{~h}$ antes do armazenamento atrasou o pico de produção de etileno dos frutos verdosos por 6 dias, porém observaram que o tratamento adotado suprimiu o desenvolvimento de cor na casca desses melões.

Houve aumento da perda de massa ao longo do armazenamento (Figura 1C), com menor perda para os tratamentos associados à atmosfera modificada (Tabela 1), não tendo efeito do 1-MCP, concordando com Lima et al. (2004), trabalhando com melão Galia. Aos 21 dias após a colheita o valor médio registrado foi de $3,32 \%$ o que representa $33,2 \mathrm{~kg} \mathrm{t}^{-1}$ de massa total perdida, verificando-se leve sinal de murcha para os tratamentos sem filme plástico. A perda de massa é uma das principais causas da deterioração no armazenamento, resultando, não apenas na perda quantitativa, o que ocasiona sérios prejuízos econômicos, pois normalmente os frutos são vendidos por unidade de massa, mas também perda qualitativa pelo enrugamento e amolecimento, dentre outros. No interior das embalagens Xtend $^{\circledR}$ ocorre maior acúmulo de vapor d'água, porém não ocorre condensação de água na superfície das mesmas, representando uma inovação tecnológica em relação a outras embalagens convencionais (Cocozza, 2003). Almeida (2002), avaliando a conservação de 


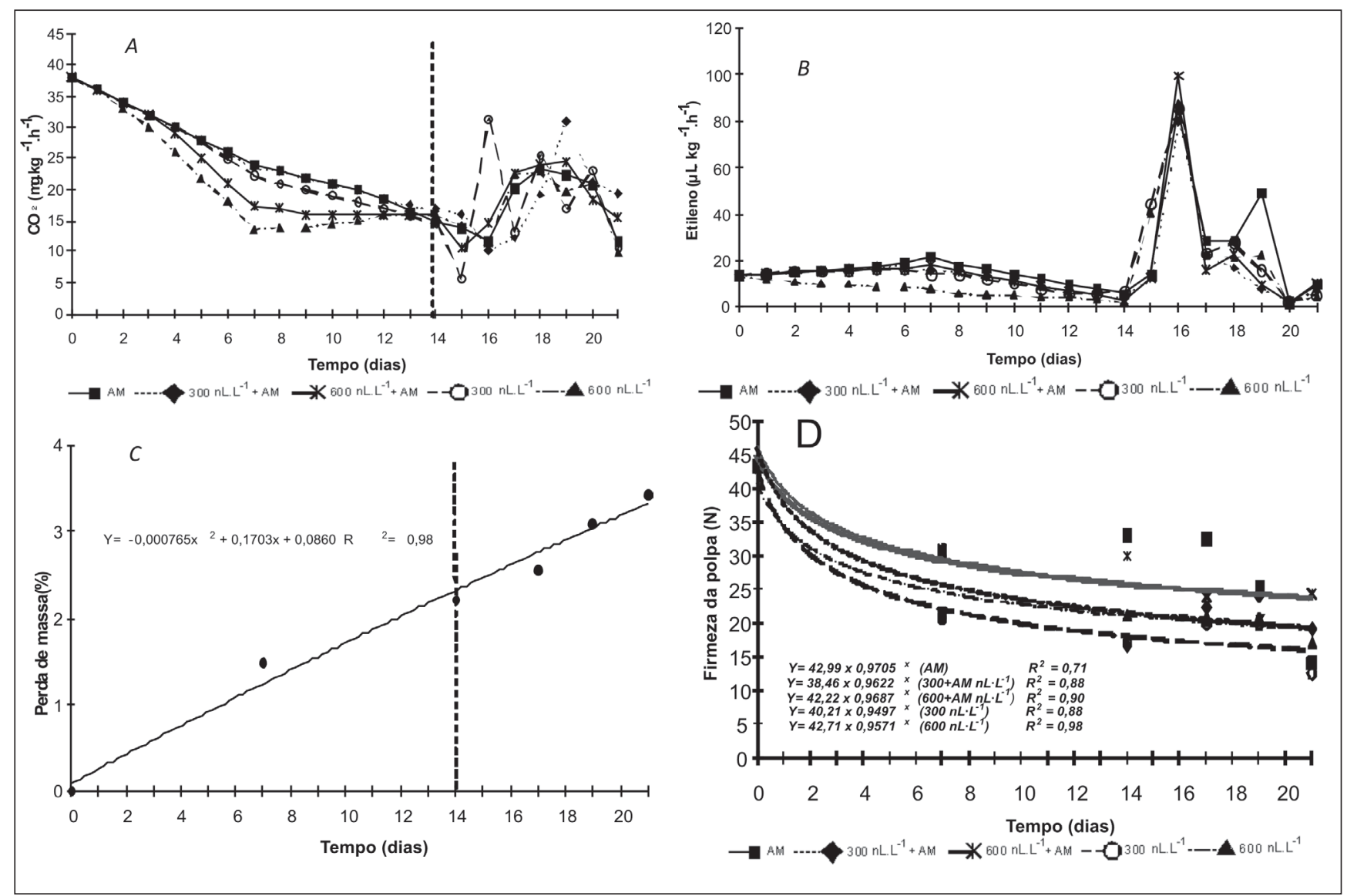

Figura 1. Atividade respiratória (A), produção de etileno (B), estimativa da perda de massa (C) e da firmeza da polpa (D) em melões Charentais, híbrido Aura Prince, armazenados a temperatura refrigerada por 14 dias $\left(9 \pm 1{ }^{\circ} \mathrm{C}\right.$ e $87 \pm 5 \%$ U.R. $)+7$ dias $\left(22 \pm 2{ }^{\circ} \mathrm{C}\right.$ e $70 \pm 5 \%$ U.R.) (respiratory rate (A), ethylene production (B), weight loss (C) and flesh firmness (D) estimation of Charentais melons, 'Aura Prince', stored under cold temperature during 14 days $\left(9 \pm 1^{\circ} \mathrm{C}\right.$ and $87 \pm 5 \%$ U.R. $)+7$ days $\left(22 \pm 2{ }^{\circ} \mathrm{C}\right.$ and $70 \pm 5 \%$ U.R. $)$ Fortaleza, Embrapa Agroindústria Tropical, 2006.

melão Cantaloupe 'Hy-Mark' tratados com 1-MCP (300 ppb) e armazenados a $5^{\circ} \mathrm{C}$, observou, aos 30 dias de armazenamento, perda de massa de $5,4 \%$ para os frutos armazenados sob atmosfera modificada com filmes plásticos X-tend ${ }^{\hat{a}}$ e de $8,4 \%$ para os frutos tratados apenas com 1-MCP.

A firmeza da polpa sofreu efeito da interação entre os fatores estudados, observando-se redução para todos os tratamentos durante o armazenamento (Figura 1D). Os frutos mantidos sob atmosfera modificada isolada ficaram mais firmes até o $19^{\circ}$ dia de armazenamento, sendo então superados pelos frutos tratados com 1-MCP. Para os frutos tratados com 1-MCP, observou-se, ao longo do armazenamento, que os frutos tratados com a maior concentração $\left(600 \mathrm{~nL} \mathrm{~L}^{-1}\right)$, na presença ou ausência da atmosfera modificada, estavam mais firmes. O efeito do 1-MCP relacionado ao retardo da evolução do amaciamento foi também verificado em melões Galia (Lima et al., 2004; Ergun et al., 2005). Em melões Charentais, Ayub et al. (1996) citam que o amaciamento está intimamente ligado à presença do etileno. Os maiores valores de firmeza da polpa para os tratamentos com atmosfera modificada podem ser devido, possivelmente, à maior concentração de $\mathrm{CO}_{2}$ no interior das embalagens (dados não mostrados) e também à menor perda de umidade durante o armazenamento, visto que a água ajuda a estabilidade estrutural da parede celular. Watkins (2006) cita que os efeitos do 1-MCP relacionados ao metabolismo da parede celular em frutos e hortaliças estão associados à redução da atividade das enzimas poligalacturonase, pectinametilesterase e endo- $\beta$-1,4-glucanase.

Houve efeito isolado dos fatores estudados para a aparência externa (Figu- ra 2A), havendo redução dessa característica ao longo do armazenamento, sendo que os frutos mantidos sob atmosfera modificada apresentaram melhor aparência final (Quadro 1). Os frutos mantidos sob atmosfera ambiente tiveram ganho de cor amarela mais cedo e apresentaram, ao final do armazenamento, leve presença de fungo na inserção do pedúnculo e aspecto de murcha com depressões escuras na casca e nas nervuras, concordando com os resultados obtidos para a perda de massa, apresentando, índices médios inferiores a 3,0 , o que representou vida útil de apenas 19 dias.

$A$ aparência interna teve leve perda da qualidade ao longo do armazenamento (Figura 2B). Os frutos tratados com $300 \mathrm{~nL} \mathrm{~L}^{-1}$ de 1-MCP, associado ou não à atmosfera modificada, apresentaram maior incidência de sementes soltas que, segundo Lima et al 


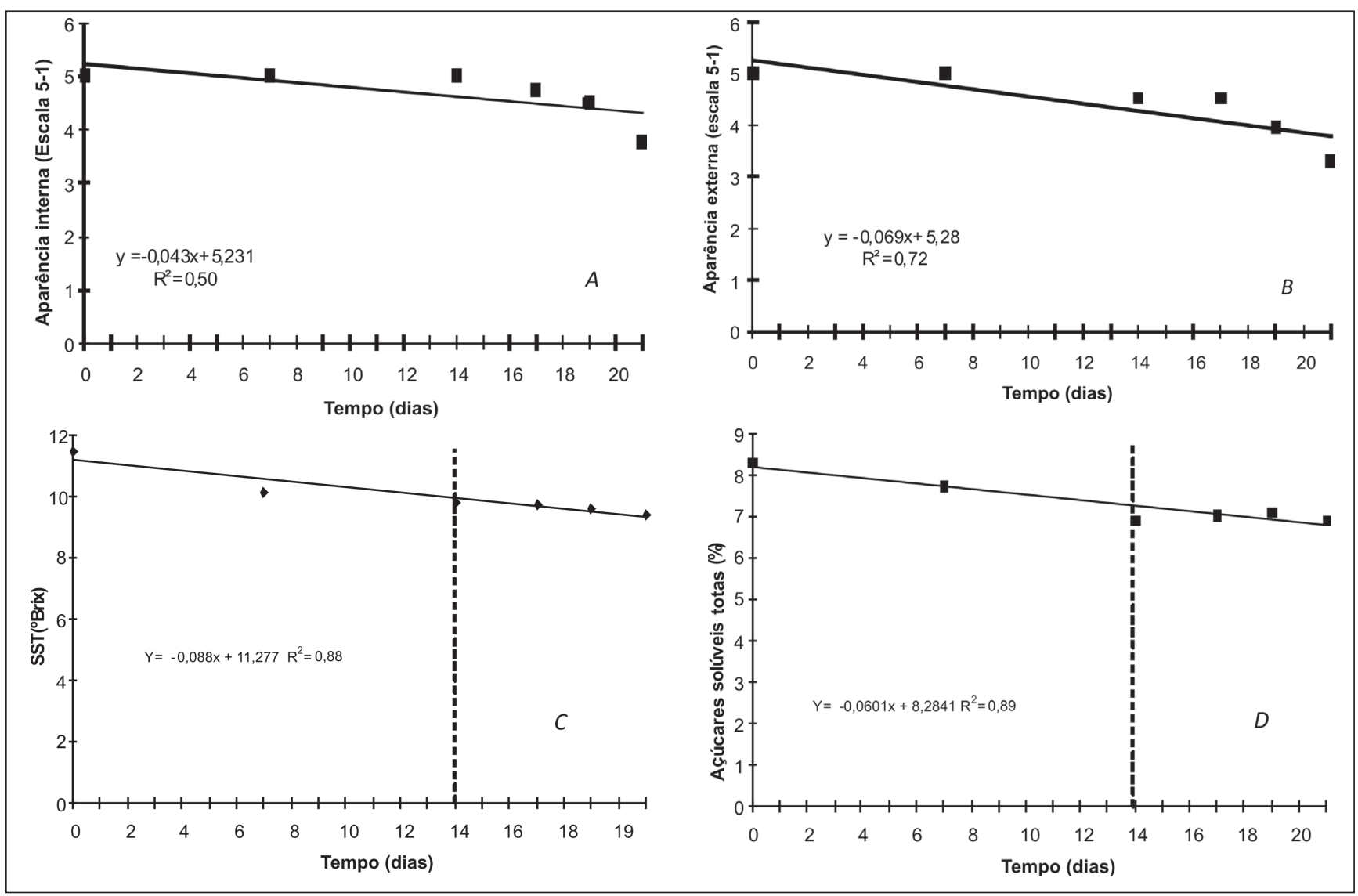

Figura 2. Estimativa da aparência externa (A), aparência interna (B), sólidos solúveis totais (C) e açúcares solúveis totais (D) em melões Charentais, híbrido Aura Prince, armazenados a temperatura refrigerada por 14 dias $\left(9 \pm 1{ }^{\circ} \mathrm{C}\right.$ e $87 \pm 5 \%$ U.R. $)+7$ dias $\left(22 \pm 2{ }^{\circ} \mathrm{C}\right.$ e $70 \pm 5 \%$ U.R.) (estimation of the external appearance (A), internal appearance (B), total soluble solids (C) and total soluble sugars (D) of Charentais melons, 'Aura Prince', stored under cold temperature during 14 days $\left(9 \pm 1^{\circ} \mathrm{C}\right.$ and $87 \pm 5 \%$ U.R. $)+7$ days $\left(22 \pm 2^{\circ} \mathrm{C}\right.$ and $70 \pm 5 \%$ U.R.). Fortaleza, Embrapa Agroindústria Tropical, 2006.

(2004) é decorrente do acúmulo de água livre em volta das sementes. A redução nos índices de aparência interna foi verificada, principalmente, após a transferência dos frutos para a temperatura ambiente (após o $14^{\circ}$ dia de armazenamento). Em pesquisas realizadas com 1-MCP não se verificou efeito sobre a aparência interna de melões.

Houve ligeiro decréscimo dos teores de sólidos solúveis totais (SST) ao longo do armazenamento (Figura 2C), também verificado por outros autores em melões do grupo Cantaloupensis (Almeida, 2002; Rodov et al., 2002 e Lima et al., 2004). O teor médio inicial e aos 21 dias foi de 11,3 e 9,4 $4^{\circ}$ Brix, respectivamente. Essa pequena redução nos teores de sólidos solúveis totais durante $\mathrm{o}$ armazenamento pode ser devida ao consumo de açúcares pelo processo respiratório dos frutos. Tendo em vista que o melão não armazena amido, fazse necessário colher os frutos com teor de sólidos solúveis adequado a fim de se obter um produto aceitável para a comercialização.

O teor médio inicial dos açúcares solúveis totais (AST) foi de $8,4 \%$, com decréscimo ao longo do armazenamento (Figura 2D), mostrando efeito apenas do fator tempo, concordando com o resultado encontrado para os sólidos solúveis totais. O resultado encontrado no presente trabalho também foi verificado por Lima et al. (2004) em melão Galia. Os mesmos autores não encontraram efeito do 1-MCP sobre os SST e os AST. Em melão, a qualidade é principalmente determinada pela quantidade de açúcares que representam os principais componentes da fração solúvel, compreendendo mais de $97 \%$. Os principais açúcares presentes em melão são a glicose e a frutose, que contribuem com quase $100 \%$ do teor de açúcares solúveis totais na fase inicial de desenvolvimento do fruto, e a sacarose que pode chegar até 50\% dos açúcares solúveis na fase final de maturação, com proporção aproximada de $25 \%$ para glicose e 25\% para frutose (Kultur et al., 2001).

Houve efeito apenas do fator tempo para o conteúdo de vitamina $\mathrm{C}$ total $(\mathrm{Fi}$ gura $3 \mathrm{~A}$ ), com redução acentuada até o $14^{\circ}$ dia de armazenamento. O teor médio inicial de vitamina $\mathrm{C}$ foi de 18,52 mg $100 \mathrm{~g}^{-1} \mathrm{MF}$, chegando a 2,83 mg 100 $\mathrm{g}^{-1} \mathrm{MF}$ aos 21 dias de armazenamento, $\mathrm{o}$ que representou redução de $84,7 \%$. Em goiabas tratadas com $900 \mathrm{~nL} \mathrm{~L}^{-1}$ de 1MCP também não foi verificado efeito sobre a concentração de ácido ascórbico (Bassetto et al., 2005).

Houve efeito isolado do fator tempo de armazenamento para o ângulo Hue (Figura 3B). Durante o armazenamento refrigerado, e logo em seguida sob condições ambiente, observou-se diminuição do ângulo Hue de 104,63 a 90,66 da região verde da casca, indicando que o amadurecimento ocorreu, em função 
da coloração da casca ter evoluído do verde acinzentado para o predominante amarelo com poucas tonalidades verdes. $\mathrm{O}$ tratamento com o filme $\mathrm{X}$-tend ${ }^{\circledR}$, atmosfera modificada, reduziu a evolução da coloração da casca principalmente quando aplicado de forma isolada (Tabela 1). O uso da atmosfera modificada durante a refrigeração, além de ter propiciado menor perda de massa, atrasou o ganho de coloração alaranjada. Porém, essa diferença foi perceptível apenas no colorímetro, pois a casca dos melões, ao final do experimento, apresentava-se predominantemente amarela para todos os tratamentos estudados, sendo esta uma característica bastante desejável durante a comercialização.

Não se verificou efeito dos tratamentos no acúmulo de etanol, encontrandose valor médio de $39,3 \mu \mathrm{L} 100 \mathrm{~g}^{-1} \mathrm{MF}$ de polpa. Em melão, a formação desse composto não é tão elevada e ocorre durante a maturação e principalmente após, em estádios mais avançados de amadurecimento (Tamura et al., 1973). Avaliando a formação de substâncias alcoólicas em melão Cantaloupe, Motomura (1994) observou que os frutos que apresentavam concentrações de substâncias alcoólicas superiores a 100 $\mu \mathrm{L} 100 \mathrm{~mL}^{-1}$ de suco estavam com "flavor" desagradável e eram de baixa qualidade.

Observou-se efeito do fator tempo para a atividade da enzima poligalacturonase na matéria fresca da polpa (Figura 3C), não verificando-se efeito da atividade da enzima pectinametilesterase. Durante os primeiros sete dias de armazenamento verificou-se redução na atividade da poligalacturonase, com maior atividade após a retirada dos frutos da câmara fria, coincidindo com maior perda de firneza da polpa, seguindo-se novamente de redução da atividade ao final do armazenamento. Em melão, substanciais despolimerização e solubilização de pectina ocorrem durante o amadurecimento (Rose et al., 1998). Porém, devido à ausência de aumento de atividade das principais enzimas relacionadas à degradação e solubilização de polímeros pécticos, poligalacturonase e pectinametilesterase, em alguns tipos de melões (McCollum et al., 1989), acha-
Tabela 1. Valores médios da perda de massa (\%), aparência externa (escala de 5 -1) e ângulo Hue da casca de melões "tipo Charentais" cv. Aura Prince, sob atmosfera modificada (AM) e submetidos a aplicação de 1-MCP.(mean values of weight loss (\%), external appearance (scale 1-5) and Hue angle of Charentais melons skin, 'Aura Prince', under modified atmosphere (AM) and submitted to 1-MCP application). Fortaleza, Embrapa Agroindústria Tropical, 2006.

\begin{tabular}{|c|c|c|c|c|c|}
\hline \multirow{2}{*}{$\begin{array}{l}\text { Características } \\
\text { avaliadas }\end{array}$} & \multicolumn{5}{|c|}{ Tratamentos } \\
\hline & AM & $\begin{array}{l}300 \mathrm{~nL} \cdot \mathrm{L}^{-1} \\
+\mathrm{AM}\end{array}$ & $\begin{array}{l}600 \mathrm{~nL} \cdot \mathrm{L}^{-1} \\
+\mathrm{AM}\end{array}$ & $300 \mathrm{~nL} \cdot \mathrm{L}^{-1}$ & $600 \mathrm{~nL} \cdot \mathrm{L}^{-}$ \\
\hline Perda de massa & $2,04 \mathrm{~b}$ & $2,30 \mathrm{~b}$ & $2,10 \mathrm{~b}$ & $3,24 a$ & $3,11 \mathrm{a}$ \\
\hline Ap. externa & $4,63 \mathrm{a}$ & $4,50 a b$ & $4,58 \mathrm{a}$ & $4,00 \mathrm{bc}$ & $4,20 \mathrm{c}$ \\
\hline${ }^{\circ}$ Hue & $102,99 \mathrm{a}$ & $97,46 \mathrm{~b}$ & $100,02 a b$ & $97,52 \mathrm{~b}$ & $97,17 \mathrm{~b}$ \\
\hline
\end{tabular}

Médias seguidas da mesma letras nas linhas não diferem estatisticamente entre si pelo teste de Tukey a $5 \%$ de probabilidade (means followed by the same letters in the line did not differ from each other, Tukey test, $5 \%$ ).

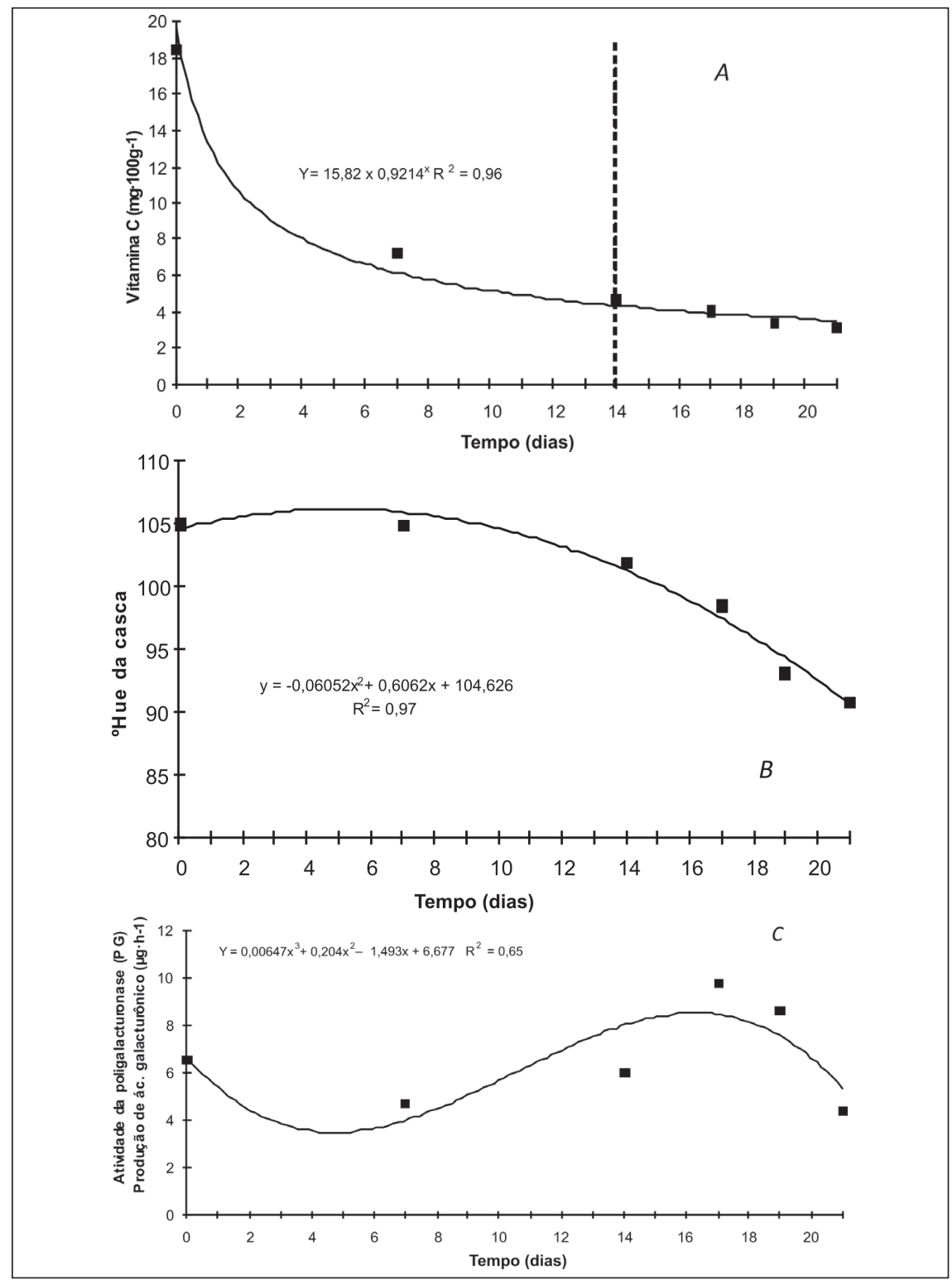

Figura 3. Estimativa da vitamina C (A), ângulo Hue da casca (B) e atividade da enzima poligalacturonase $(C)$ em melões Charentais, híbrido Aura Prince, armazenados a temperatura refrigerada por 14 dias $\left(9 \pm 1{ }^{\circ} \mathrm{C}\right.$ e $87 \pm 5 \%$ U.R. $)+7$ dias $\left(22 \pm 2^{\circ} \mathrm{C}\right.$ e $70 \pm 5 \%$ U.R.)(estimation of vitamin C (A), Hue angle of skin (B) and activity of poligalacturonase enzyme (C) of Charentais melons 'Aura Prince', stored under cold temperature during 14 days $\left(9 \pm 1^{\circ} \mathrm{C}\right.$ and $87 \pm 5 \%$ U.R. $)+$ 7 days $\left(22 \pm 2^{\circ} \mathrm{C}\right.$ and $70 \pm 5 \%$ U.R.). Fortaleza, Embrapa Agroindústria Tropical, 2006. 
va-se que, possivelmente, a modificação de polímeros pécticos e componentes hemicelulósicos era causada pela presença de outras enzimas, como as $\beta$ galactosidases (Ranwala et al., 1992). Todavia, Hadfield et al. (1998), estudando a expressão gênica da poligalacturonase durante o amadurecimento de melões Charentais 'F1 Alpha' verificaram aumento na atividade de enzimas que degradam a pectina e o aparecimento de três mRNAs da poligalacturonase em estádios mais avançados de amadurecimento. De maneira geral, esses resultados sugerem que a degradação da pectina mediada pela poligalacturonase ocorre após os estádios iniciais de amolecimento do fruto e provavelmente contribui significativamente para os estádios de amadurecimento excessivo incluindo amolecimento e deterioração (Hadfield \& Bennett, 1998).

A aplicação do 1-MCP na concentração de $600 \mathrm{~nL} \mathrm{~L}^{-1}$ reduziu a atividade respiratória e a produção de etileno, principalmente quando os frutos foram armazenados sob refrigeração. A associação do 1-MCP com a atmosfera modificada $\left(\mathrm{X}\right.$-tend $\left.{ }^{\circledR}\right)$, produziu melhores resultados para a firmeza da polpa, perda de massa, aparência externa. A atmosfera modificada, isoladamente, foi eficiente em reduzir a perda de massa, manter melhor aparência externa e maior ângulo Hue da casca, porém não foi suficiente para retardar o amarelecimento dos frutos. Com base na aparência externa, a vida útil póscolheita dos frutos armazenados sob atmosfera modificada isolada e dos frutos tratados com 1-MCP e armazenados sob atmosfera modificada foi de 21 dias (14 dias sob refrigeração e 7 dias ambiente), enquanto que dos frutos tratados apenas com 1-MCP foi de 19 dias (14 dias sob refrigeração e 5 dias ambiente).

\section{AGRADECIMENTOS}

A CAPES pelo auxílio financeiro.

\section{REFERÊNCIAS}

AGRIANUAL. 2004. Anuário da Agricultura Brasileira, São Paulo: FNP Consultoria e Agroinformativos, 496p.
ALMEIDAAS; FILGUEIRAS, HAC; MENEZES JB; ALVES RE; PEREIRA MEC; ALMEIDA AV. 2001 (a). Atividade respiratória e produção de etileno em diferentes híbridos de melão cultivados no pólo agrícola Mossoró-Açú. In: CONGRESSO BRASILEIRO DE OLERICULTURA, 41. Resumos... Brasília: SOB (CD-ROM).

ALMEIDA AS. 2002. Conservação de melão cantaloupe 'Hy-Mark' tratado com 1-MCP após a colheita. Mossoró: ESAM. 143p. (Tese mestrado).

ALMEIDA AS; ALVES RE; FILGUEIRAS HAC; MENEZES JB; PEREIRA MEC; MOURA CFH. 2003. Conservação de melão Cantaloupe 'Hy-Mark' tratado em póscolheita com 1-metilciclopropeno (1-MCP) In: CONGRESSO BRASILEIRO DE OLERICULTURA, 43. Resumos... Recife: $S O B$ (CD-ROM).

ARAÚJO JLP; VILELA NJ. 2003. Aspectos econômicos. In: SILVA HR; COSTA ND. Melão Produção: aspectos técnicos. Brasília: Embrapa Informação Tecnológica. p. 15-18.

AYUB R; GUIS M; BEN AMOR M; GILLOT L; ROUSTAN JP; LATCHÉ A; BOUZAYEN M; PECH JC. 1996. Expresión of acc oxidase antisense gene inhibits ripening of cantaloupe melon fruits. Nature Biotechnology, 14: 862866.

BASSETTO EAP; JACOMINO AL; PINHEIRO AND; KLUGE RA. 2005. Delay of ripening of 'Pedro Sato' guava with 1methylcyclopropene. Postharvest Biology and Technology 35: 303-308.

BLANKENSHIP SM; DOLE JM. 2003. 1methylciclopropene: a review. Postharvest Biology Technology 28: 1-25.

COCOZZA FDM. 2003. Maturação $e$ conservação de manga 'Tommy Atkins' submetida à aplicação pós-colheita de 1metilciclopropeno. Campinas: UNICAMP,. 198p. (Tese doutorado).

ERGUN M; JEONG J; HUBER DJ; CANTLIFFE DJ. 2005. Suppression of ripening and softening of Galia melons by 1methylcyclopropene applied at preripe or ripe stages of development. HortScience, 40: 170175.

HADFIELD KA; BENNETT AB. 1998. Polygalacturonases: Many genes in search of function. Plant Physiology 117: 337-343.

HADFIELD KA; ROSE JKC; YAVER DS; BERKA RM; BENNETT AB. 1998. Polygalacturonase gene expression in ripe melon fruit supports a role for polygalacturonase in ripening-associated pectin disassembly. Plant Physiology 117:363373.

HULBERT GJ; BHOWMIK SR. 1987. Quality of fungicide treated and individually shrink wrapped tomatoes. Journal of Food Science 52: 1293

IBGE: Instituto Brasileiro de Geografia e Estatística. 2006. 14 de outubro. Disponível em: http://www.ibge.gov.br.

KATO-NOGUCHI H; WATADA AE. 1997. Effects of low-oxygen atmosphere on ethanolic fermentation in fresh-cut carrots. J. Amer. Soc. Hort. Sci. 122: 107-111.
KULTUR F; HARRISON HC; STAUB JE. 2001. Spacing and genotype affect fruit sugar concentration, yield, and fruit size of muskmelon. HortScience 36: 274-278.

LANA MM; FINGER FL. 2000. Atmosfera Modificada e Controlada: Aplicação na Conservação de Produtos Hortícolas. Brasília, DF: Embrapa,. 34p.

LIMA MAC; ALVES RE; BISCEGLI CI; FILGUEIRAS HAC; COCOZZA FDM. 2004. Conservação de melões Gália 'Solar King' tratados com 1-metilciclopropeno. Horticultura Brasileira, 22: 121 - 126.

McCOLLUM TG; HUBER DJ; CANTLIFFE DJ. 1989. Modification of the polyuronides and hemicellulose during muskmelon fruit softening. Physiologia Plantarum 76: 303-308.

MORETTI CL; ARAÚJO JLP. 2003. Tecnologia de Pós-colheita e comercialização. In: SILVA HR; COSTA ND. Melão Produção: aspectos técnicos. Brasília: Embrapa Informação Tecnológica, p. 121-129.

MOTOMURA Y. 1994. Formation of alcohol substances in muskmelon: variation among cultivars and maturity. Scientia Horticulturae 58: 343-350.

NAKHASI S; SCHLIMME D; SOLOMOS T. 1991. Storage potential of tomatos harvested at the breaker stage using modified atmosphere packaging. Journal of Food Science 56: 5559.

RANWALA AP; SUEMATSU C; MASUDA H. 1992. The role of b-galactosidases in the modification of cell wall components during muskmelon ripening. Plant Physiology 100: 1318-1325.

RODOV V; HOREV B; VINOKUR Y; COPEL A; AHARONI Y; AHARONI N. 2002. Modified-atmosphere packaging improves keeping quality of Charentais-type melons. HortScience 37: 950-953.

ROSE JKC; HADFIELD KA; LABAVITCH JM; BENNETT AB. 1998. Temporal sequence of cell wall disassembly in rapidly ripening melon fruit. Plant Physiology 117: 345-361.

STROHECKER R; HENNING HM. 1967. Analisis de vitaminas: métodos comprobados. Madrid: Paz Montalvo, 428p.

TAMURA T; NAKASHIMA T; IMAKAWA S; HIGUCHI K; MINO Y. 1973. Studies on melon storage: Effects of maturity and gás component on the quality during storage. Memoirs of the Faculty of Agriculture Hokkaido University 9: 47-53.

VILAS-BOAS EVB; CHITARRA AB; MALUF WR; CHITARRA MIF. 2000. Modificações texturais de tomates heterozigotos no loco alcobaça. Pesquisa Agropecuária Brasileira 35: 1447-1453.

YEMN EW; WILLIS AJ. 1954. The estimation of carbohydrate in plant extracts by anthrone. The Biochemical Journal 57: 505 - 514.

WATKINS CB. 2006. The use of 1methylcyclopropene (1-MCP) on fruits and vegetables. Biotechnology Advances p.1-21 